\title{
Some aspects of forecasting the post-mining substratum deformation for evaluation of its influence on constructions
}

\author{
Piotr Strzałkowski ${ }^{1}$, Roman Ścigała ${ }^{1,}$ Katarzyna Szafulera ${ }^{1 *}$ \\ ${ }^{1}$ Silesian University of Technology, Faculty of Mining and Geology, Gliwice, Poland
}

\begin{abstract}
Some problems have been discussed, connected with performing predictions of post-mining terrain deformations. Especially problems occur with the summation of horizontal strain over long time intervals as well as predictions of linear discontinuous deformations. Of great importance in recent years is the problem of taking into account transient values of deformations associated with the development of extraction field. The exemplary analysis has been presented of planned extraction influences on two characteristic locations of building structure. The proposal has been shown of calculations with using transient deformation model allowing to describe the influence of extraction advance influence on the value of coefficient of extraction rate $c$ (time factor), according to own original empirical formula.
\end{abstract}

Keywords: post-mining deformations, transient deformation state

\section{Introduction}

For the first time, mining operations were carried out under the built-up area at the beginning of the XIXth century. Mining works under the Belgian city of Liege caused damage to buildings, which prompted local mining engineers to conduct geodetic surveys. The results of these measurements became the basis for the development of the first theories of forecasting the impact of underground mining operations on the surface. The first solutions were often characterized by low accuracy or were mathematically incorrect. Conducted for many years systematic research related to the above topics allowed to develop a number of theories that are characterized by sufficient accuracy of prediction for mining practice. The review of the theories of mining area deformation, starting with the first methods, can be found among others in $[1,2,3,4,5]$.

The theory of W. Budryk - S. Knothe [6] enjoys the greatest popularity in Poland. It is characterized by the simplicity of the mathematical model. Long period of its use has resulted in a very good understanding of the parameters that should be taken into account for given mining - geological conditions. An additional reason for its popularity is the fact

*Corresponding author: katarzyna.szafulera@polsl.pl 
that a number of software have been developed that allow easy and quick calculations [7, 8].

Considering the above statements, one could mistakenly believe that performing forecasts of the impact of mining operations on the surface is a very simple task. Despite many years of experience in this area however, there are still some doubts and questions for which there are no unambiguous answers.

The first of the doubts is connected with the summation of the values of deformation indices in long time intervals. According to S. Knothe [6], horizontal strain should be summed up in 10-year periods. B. Skinderowicz presented the view, that the values of deformations indices should be reduced by half in two-year periods. B. Drzęźla [9], J. Kwiatek [10, 11] and J. Białek [7] considered the concept of the so-called effective deformations, that bases on the assumptions taken from rheological models. J.Białek incorporated in his software a functional relationship, that expresses the reduction of strain caused by the extraction of a given mining field for the purpose of assessment of its influence on the building object:

$$
\varepsilon(t)_{e}=\int_{0}^{t} \frac{d \varepsilon(\tau)}{d \tau}\left[A_{r e l}+\left(1-A_{r e l}\right) e^{-(t-\tau) / T_{r e l}}\right] d \tau
$$

$$
\text { where: } \begin{aligned}
\varepsilon(t) & - \text { actual horizontal strain [\%o], } \\
\varepsilon(t)_{e} & \text { - effective horizontal strain [\%o], } \\
t & \text { - time [years] } \\
A_{r e l} & - \text { relaxation coefficient, } \\
T_{r e l} & \text { - relaxation time [years]. }
\end{aligned}
$$

Fig. 1 graphically presents the mentioned above strain reduction methods, according to the works $[4,12]$.

In the Upper Silesia Basin, intensive mining extraction has been carried out for over 200 years. If we were to sum up the values of horizontal strain in some regions for long periods of time, it would reach a very large value. When considering the possibility of transferring such large deformations from subsoil layers to given construction, one would have to conclude that carrying out such extraction would lead to mass construction disasters which - in fact, did not take place, of course. In the light of this statement, so-called phenomena of "strain relaxation" in accordance with formula (1) seems to be a reasonable solution. An alternative to this proposal may be to assess the objects resistance to mining damages after finishing all post-mining movements being the effect of subsequent extraction, e.g. conducted according to given mining plan of operation.

The issue of the horizontal strain summation in long time intervals is also connected with the problem of the discontinuous linear deformations occurrence. As it is known, the occurrence of these deformations is closely related to the values and direction of extreme horizontal strain values and the course of tectonic disturbances (especially their outcrops on the floor of overburden layers). Such conclusions resulting from detailed analyzes were presented, among others, in the work [13]. It should be noted that methods for forecasting of this type of deformation have not been sufficiently developed so far, which is a serious difficulty in assessing the complex prediction of impact of underground mining works on the surface.

Another important problem regarding forecasts is making calculations of transient values of deformation indices or their extreme values resulting from the movement of the extraction front. This problem is devoted to more attention in the next part of the paper. 


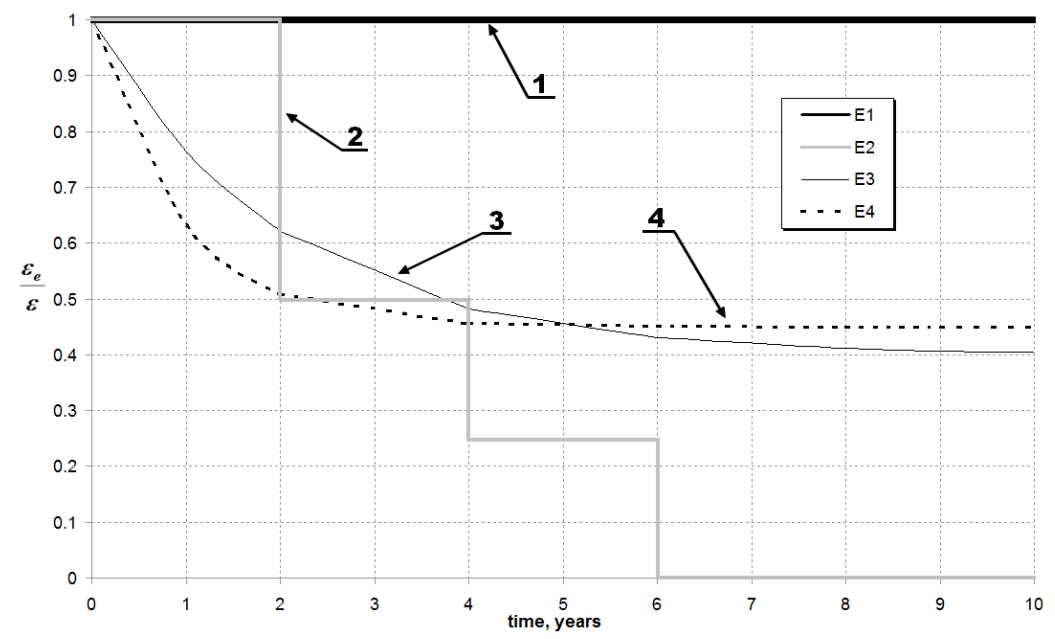

Fig. 1. Time-dependent reduction of horizontal strain influence on the object: 1-by S. Knothe, 2by B. Skinderowicz, 3-by J. Białek, 4-by J. Kwiatek

\section{The exemplary analysis of post-mining deformation distribution over time}

Considering the problem concerning the course of deformation state changes over time, it was assumed for calculation purposes, that mining extraction is planned with two longwalls (Fig. 2). Basic information on the mining-geological conditions in the area of considered longwalls is given in Table 1 . The table consists of two used data sets, regarding different speed of extraction: $3 \mathrm{~m} /$ day and $10 \mathrm{~m} /$ day.

All calculations were performed with using the DEFK-Win software [8], based on the theory of S. Knothe [6]. In calculations, the following average (for Upper Silesian Basin mining-geological conditions) values of parameters were used: coefficient of roof control $a=0.8$, tangent of the angle of main influence range $\operatorname{tg} \beta=2.0$, proportionality coefficient of Avershin's relationship $B=0.32 \mathrm{r}$, extraction boundary $d=0 \mathrm{~m}$.

Analyzing the predicted values of deformation indices, which occur as a result of conducting planned mining extraction at a certain time $t$, the location of the calculation point in relation to the extraction field should be taken into account. When the object is located at a certain distance outside the horizontal plan of extraction field, the values of deformation indices constantly increase until they reach maxima, which are also the final values. This is illustrated by the example presented below for point No 1, located outside planned extraction fields, near starting roadway, as shown in Fig. 2.

Table 1. Basic data on considered mining extraction

\begin{tabular}{|c|c|c|c|c|c|}
\hline $\begin{array}{c}\text { Seam No / } \\
\text { extr. rate }\end{array}$ & \multirow{2}{*}{$\begin{array}{c}\text { Longwall } \\
\text { No }\end{array}$} & \multirow{2}{*}{$\begin{array}{c}\text { Extraction } \\
\text { start date }\end{array}$} & \multirow{2}{*}{$\begin{array}{c}\text { Extraction } \\
\text { end date }\end{array}$} & $\begin{array}{c}\text { Thickness } \\
\text { of deposit }\end{array}$ & $\begin{array}{c}\text { Depth of } \\
\text { extraction }\end{array}$ \\
\cline { 1 - 3 }$[\mathrm{m} / \mathrm{day}]$ & & & {$[\mathrm{m}]$} & {$[\mathrm{m}]$} \\
\hline $207 / \mathrm{v}_{03}$ & 718 & $01-07-2018$ & $20-05-2019$ & 2.5 & 665 \\
\hline $207 / \mathrm{v}_{03}$ & 728 & $21-05-2019$ & $15-09-2019$ & 2.5 & 670 \\
\hline $207 / \mathrm{v}_{10}$ & 718 & $01-07-2018$ & $06-10-2018$ & 2.5 & 665 \\
\hline $207 / \mathrm{v}_{10}$ & 728 & $07-10-2018$ & $11-11-2018$ & 2.5 & 670 \\
\hline
\end{tabular}




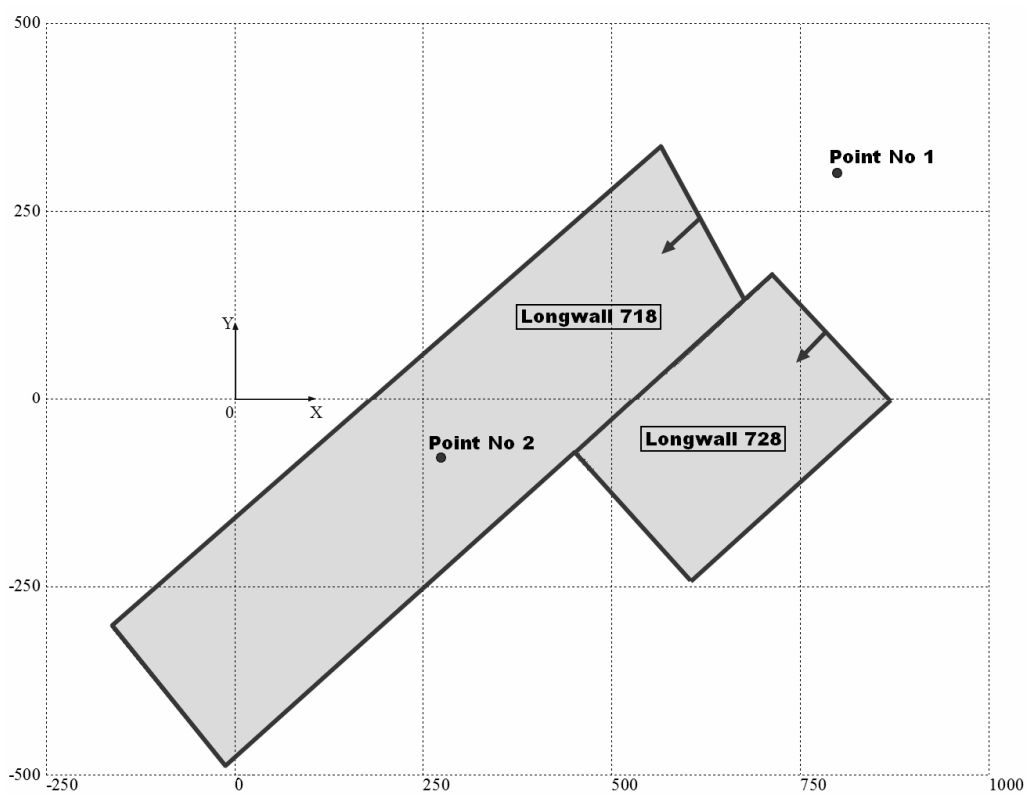

Fig. 2. The sketch of considered extraction fields plan view and location of calculation points

Calculations were performed assuming the immediate influence model - for every considered extraction front position, $100 \%$ of influence reaches the surface level instantaneously (without any delay). Fig. 3 shows the course of subsidence over time, Fig. 4 and 5 respectively of maximum tilt $T_{\max }$ and principal horizontal strain $E_{l}$. As it can be seen from the presented figures, final values of all the above-mentioned deformation indices are also the maximum values for point No 1 located outside horizontal plan of extracted area.

Although subsidence for this point reaches relatively small value of $190 \mathrm{~mm}$, tilt of $2.46 \%$, but horizontal strain of $2.46 \%$ will fall in the range of second category of mining areas (between $1.5 \%$ and $3 \%$ ). Therefore, it can be concluded, that making more detailed predictions of deformation state in case of such location of the object is not obligatory.

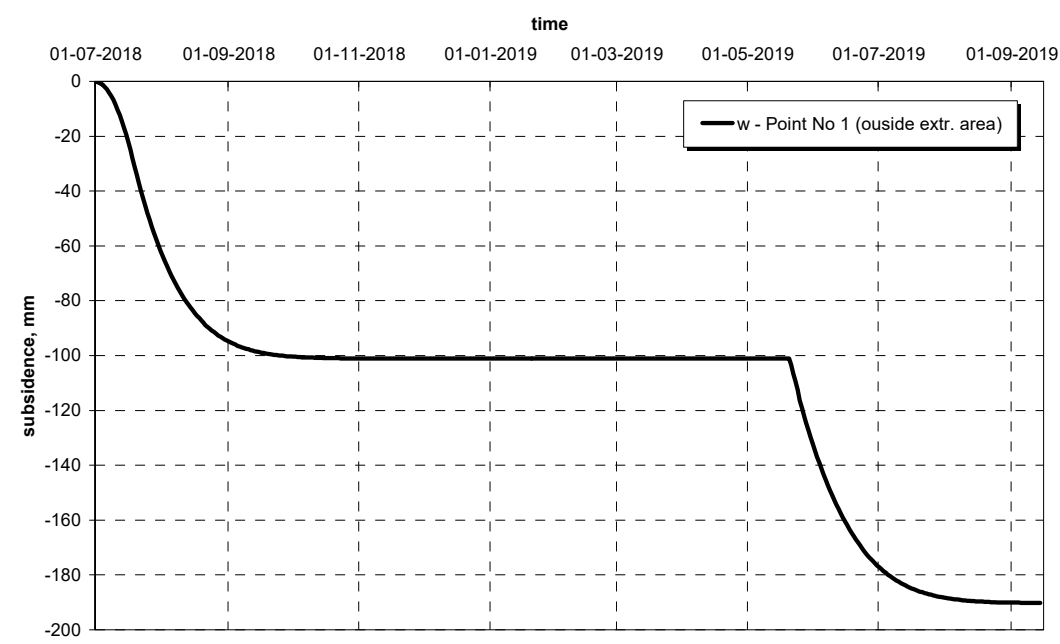

Fig. 3. The course of subsidence over time for point No 1 


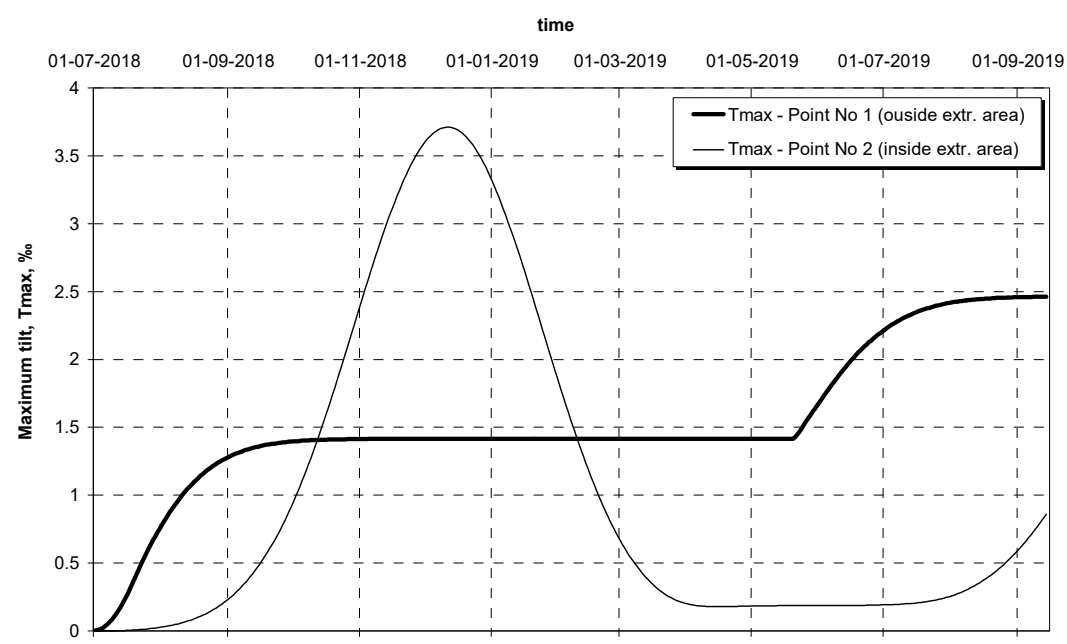

Fig. 4. The course of maximum tilt $T_{\max }$ over time for points No $1 \& 2$

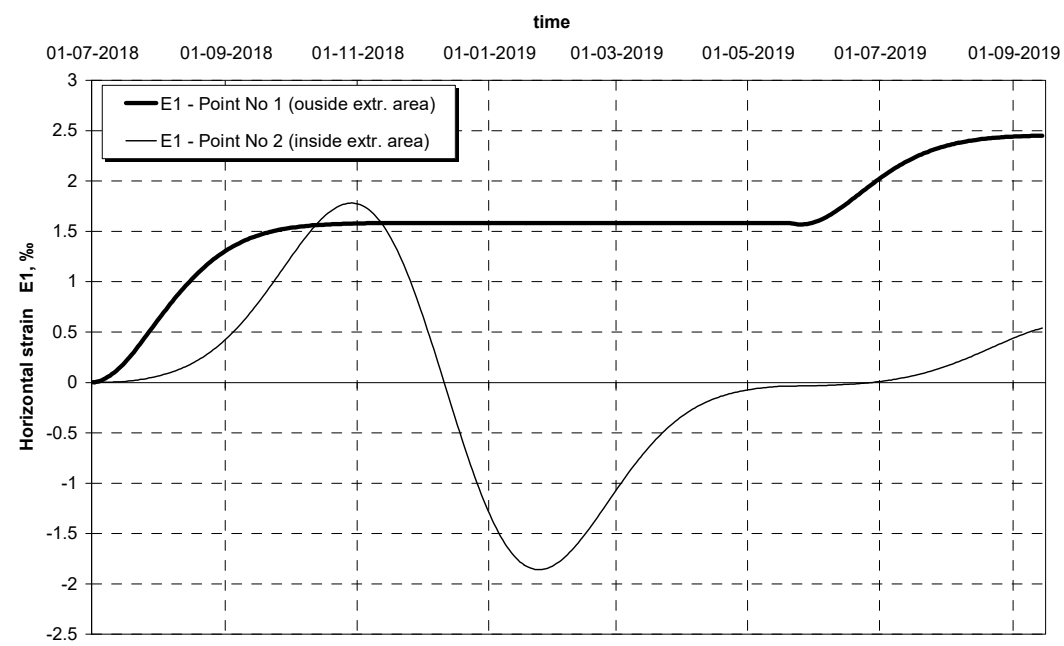

Fig. 5. The course of principal horizontal strain $E_{l}$ over time for points No $1 \& 2$

Different situation arises in case of point located directly above the extraction field - for example point No 2 in Fig. 2. In this case, one should also take into account the model of transient deformations. For further analysis, the proposition of S. Knothe expressed by the following equation [6] was taken into account:

$$
\frac{d w(t)}{d t}=c \cdot\left(w_{k}(t)-w(t)\right)
$$

where: $w_{k}(t)$ - final (asymptotic) subsidence,

$w(t) \quad$ - transient subsidence,

$c \quad$ - coefficient of subsidence rate (often called ,time factor”).

For discretized model (with the assumption: $w_{k}(t, x)=$ const. $=w_{k}$ ) with initial condition: for $t=0 \Rightarrow w(t)=0$, the solution to equation (2) has the form:

$$
w(t)=w_{k} \cdot\left(1-e^{-c t}\right)
$$

This solution is wide-spread used in Poland, however other models are utilized in different countries. Detailed description one can find, among others, in [3, 4, 12]. 
An important problem discussed in $[12,14]$ is the influence of the extraction advance rate on the course of deformations changes over time. This is reflected in the correlation between the value of coefficient $c$ and the speed of the extraction front progress. Therefore, for further analyzes that take into account the extraction speed, it was decided to use the proposal of an empirical formula presented in [15]:

$$
c=1.463 \cdot\left(\frac{v}{H}\right)^{0,847}
$$

where: $v$ - the speed (rate) of extraction front, [m/day]

$H$ - the depth of extraction, [m].

This formula has been worked out on the basis of analyses of survey results taken from Upper Silesia Basin coal mines. The exponent value in the formula (4) is close to 1, but authors concluded that the formula should not be simplified, for the reason that a constant value of the ratio $\frac{c}{r \cdot v}(r$ - the radius of main influence range) would be obtained in such case, so changes in the speed of extraction would not affect the slope of the transient profile of subsidence trough, which stays in contradiction with the results of the measurements.

Calculations of deformation indices values were performed for the following speeds of the extraction and theoretical models:

- Extraction speed $v=3 \mathrm{~m} /$ day. Immediate influences $(c \rightarrow \infty)$ model and delayed influences model described by equation (3) with the value of coefficient $c$ according to equation (4): $c=0.0151 /$ day.

- Extraction speed $v=10 \mathrm{~m} /$ day. Immediate influences model and delayed influences model described by equation (3) with the value of coefficient $\mathrm{c}$ according to equation (4): $c=0.0421 /$ day.

The calculations results of the maximum tilt and maximum horizontal strain are presented together for all of the above variants in figures $6-7$.

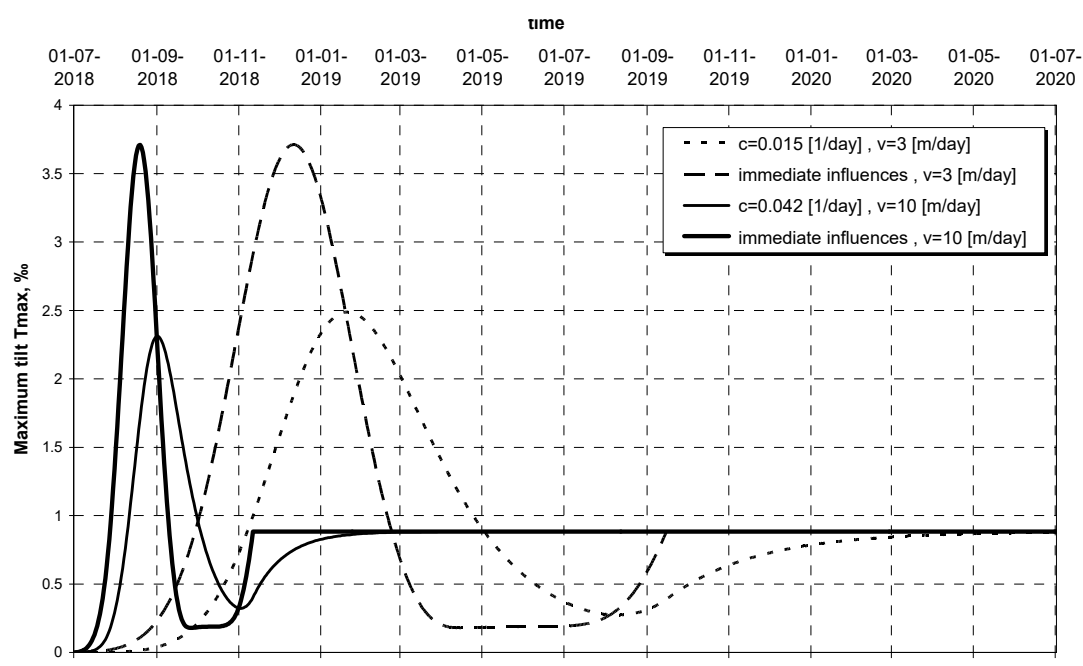

Fig. 6. The course of maximum tilt over time for point No 2 


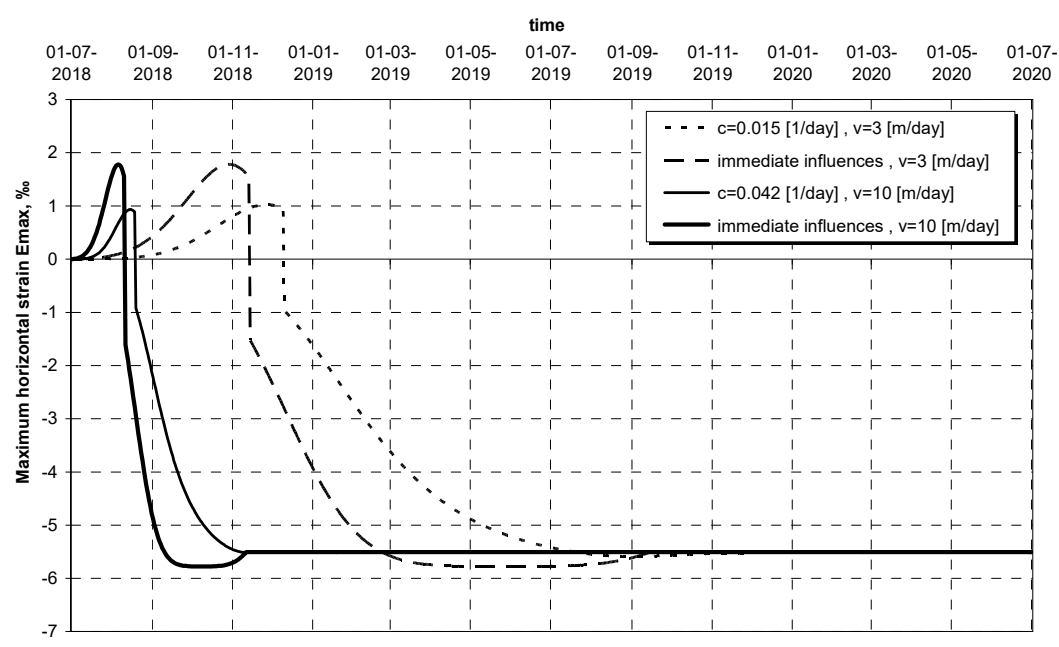

Fig. 7. The course of maximum horizontal strain over time for point No 2

As it can be concluded from the graph showing the course of horizontal strain for the considered calculation variants (Fig. 7), positive values temporarily occurred at the considered object location. This means that the object will subjected to horizontal tensile strain. Ignoring this fact in the analysis of the extraction influence on the object would be a certain inaccuracy, especially considering the low tensile strength of construction elements. Presented results stay in agreement with the analyses published in [12].

A separate problem is the impact of large increase of deformation over time, particularly the subsidence rate. In the case under presented consideration, using the proposal described in [14], there will be subsidence rate from the range of category Ib with the extraction front speed $3 \mathrm{~m} /$ day and the category III at the extraction speed of $10 \mathrm{~m} /$ day.

\section{Conclusions}

Analyzes presented in this work allow to make the following final statements and remarks:

1. The problem of post-mining deformations predictions has now become simplified due to the availability of appropriate mathematical models and specialized software. Nevertheless, when making predictions for long time intervals, there are still some doubts, especially considering horizontal strain summation procedure. This problem is also related to the still unresolved issue of forecasting linear discontinuous deformations, that often arise as an effect of large tensile strain. Such deformations, occurring presently more often than in the past, are particularly dangerous for building objects. Thus, the importance of the above problem is still necessary to be emphasized.

2. Forecasts of continuous deformations should include not only determination of asymptotic values of deformation indices, but also their time-extreme values and the rate of their changes over time. Detailed analyzes in the above-mentioned scope should be carried out especially in case of considered object location directly above planned extraction field. Such analyzes allow, among others, determination of transient values of horizontal tensile strain, which is worse tolerated by typical urban construction than compressive one. The quality of the forecast in such cases is decisively influenced by the adoption of the appropriate 
values of the parameter characterizing the deformation kinematics - time factor

" $c$ ". In connection with the above, authors recommend using the formula (4).

\section{References}

1. M. Chudek: Geomechanics and basics of management of environmental protection in mining and post-mining areas. Publishing House of the Silesian University of Technology. Gliwice (2010) (in Polish).

2. A. H. Goldreich: Die Theorie der Bodensenkungen Kohlengebieten. Verlag von Julius Springer. Berlin (1913) (in German).

3. Kratzsch H.: Mining Subsidence Engineering. Springer-Verlag. Berlin, Heidelberg, New York (1983).

4. P. Strzałkowski: The outline of the protection of mining areas. Publishing House of the Silesian University of Technology. Gliwice (2010) (in Polish).

5. J. Zych, B. Drzęźla, P. Strzałkowski: Forecasting of land surface deformations due to underground mining. Publishing House of the Silesian University of Technology, script No. 1684. Gliwice (1993) (in Polish).

6. S. Knothe: Forecasting the impact of mining exploitation. „Śląsk” Publishing House. Katowice (1984) (in Polish).

7. J. Białek: Algorithms and software for forecasting of mining area deformations. Publishing House of the Silesian University of Technology, monograph series, No. 42. Gliwice (2003) (in Polish).

8. R. Ścigała: Computer aided prediction of rock mass and land surfaces deformations caused by underground mining extraction. Publishing House of the Silesian University of Technology. Gliwice (2008) (in Polish).

9. B. Drzęźla: The description of software for predictions of rock mass deformation due to mining extraction - state of the art. Transactions of Silesian University of Technology, mining series, No. 165. Gliwice (1989) (in Polish).

10. J. Kwiatek: On rheological aspects of the threat of building constructions located in mining areas. Scientific Works of Central Mining Institute, No. 827, Katowice (1997) (in Polish).

11. J. Kwiatek (red.): Protection of building objects in mining areas. Publishing House of Central Mining Institute. Katowice (1997) (in Polish).

12. A. Kowalski: Transient deformations of land surface in the light of prediction quality. Scientific Works of Central Mining Institute, No. 871. Katowice (2007) (in Polish).

13. P. Strzałkowski, R. Ścigała: The causes of mining induced ground steps occurrence - case study from Upper Silesia in Poland. Acta Geodynamica et Geomaterialia. Vol.14 No. 3. Prague (2017).

14. A. Sroka: Dynamics of mining extraction from the point of view of mining damages. Publishing House of the Mineral and Energy Economy Research Institute of the Polish Academy of Sciences, Cracow (1999) (in Polish).

15. P. Strzałkowski, W. Piwowarski, R. Ścigała: The influence of extraction speed on the value of the coefficient of subsidence rate. Submitted for printing (in Polish).

16. A. Kowalski: Problems of prediction of land surface deformation in Upper Silesia Basin. Scientific Works of Central Mining Institute, special issue, V/2007. Katowice (2007) (in Polish). 